\title{
Tropicalismo, nacionalismo e contracultura: as afinidades entre a canção e o teatro tropicalistas (1966-1969).
}

Vinicius Milani $^{1}$

\section{RESUMO}

O "movimento" Tropicalista constituiu-se e consolidou-se no período de 1966 e 1969, dialogando com as diversas esferas da produção cultural brasileira. As encenações das peças O Rei da vela (1933) e Roda Viva (1968), ao lado do álbum Tropicália ou Panis et Circensis (1968) e do compacto É proibido proibir (1968) representam diferentes respostas, na produção teatral e musical, de um processo que causou grande impacto na cultura brasileira, e especificamente entre as esquerdas, que cristalizavam uma produção artística com diferenciadas propostas nacionais-populares. As inovações, incorporações, rupturas, e a radicalização estética operada por Caetano Veloso e José Celso, são temas abertos à análise em torno do diálogo entre suas produções e das críticas às propostas nacionaispopulares. Em nossa pesquisa, pretendemos analisar tanto os debates em torno dos álbuns e das peças, como as suas letras e encenações. Nosso objetivo é lançar luz sobre as afinidades existentes entre as obras dos artistas destacados, e como essas afinidades nos permitem problematizar a relação entre produção cultural e processo social de determinado período da história brasileira.

Palavras-Chave: tropicalismo; nacionalismo; arte e sociedade; ditadura militar.

Mestrando em Sociologia pelo programa de pós-graduação da Universidade Federal do Paraná (UFPR). Pesquisador vinculado ao grupo "Cultura, política e movimentos sociais na América Latina”. A atual pesquisa contou com o apoio da CAPES. E-mail: vinicius.tmilani@gmail.com 


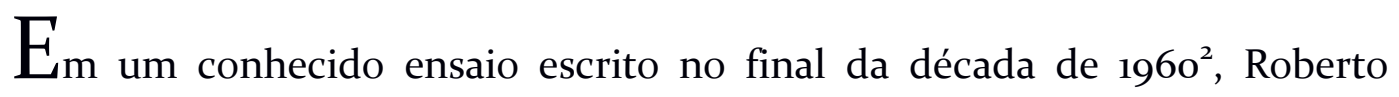

Schwarz (2008, p.71-73), em meio a um processo intenso de transformações da sociedade brasileira, que naquele momento vivia sob uma ditadura militar, apontava que o momento cultural brasileiro no pós-golpe era de relativa hegemonia da esquerda, composta de um amplo imaginário que unia uma série de artistas e intelectuais envoltos em diferentes projetos de resistência aos militares, envolvendo, sobretudo, certos estratos da classe média intelectualizada e os jovens universitários em meio a seus impasses ideológicos. Copartícipe desse processo, entre 1967 e 1969, surgiu uma nova resposta em relação às demandas artísticas e culturais que ficou conhecida como "movimento" Tropicalista; trazia consigo todo um conjunto de referenciais antagônicos, paradoxais da política e da estética, tematizava elementos de ruptura, a incorporação e a inovação relacionadas às propostas culturais consagradas, até então, pelo paradigma do nacionalismo de esquerda.

A emergência desse movimento, em meados dos anos 1960, é um tema amplamente explorado por pesquisadores situados nas diferentes áreas das Ciências Humanas. Boa parte das pesquisas ${ }^{3}$ existentes em torno do tema situa a emergência das obras que foram identificadas, historicamente, como

\footnotetext{
2 Durante a ditadura militar, Roberto Schwarz exilou-se na França, onde redigiu o ensaio Cultura e política, 1964-1969, publicado originalmente na revista Les Temps Modernes, de Jean-Paul Sartre, trazido para o Brasil em 1978. Marcos Napolitano (2010, p.184) alerta para o quadro histórico no qual o artigo fora escrito: "sob o impacto de uma segunda derrota política - o recrudescimento do regime militar após o AI-5 e a sensação de 'vazio cultural' que tomou conta da esquerda após a censura e o exílio dos seus principais criadores".

3 Sobre os trabalhos que demarcam a emergência das obras identificadas como "tropicalistas" a partir de 1967, consultar: DUNN, Christopher. Brutalidade Jardim: A Tropicália e o surgimento da contracultura brasileira. São Paulo: Editora Unesp, 2009; NAPOLITANO, Marcos. Seguindo a canção: Engajamento político e indústria cultural na MPB (1959-1969). São Paulo: Versão digital revista pelo autor, 2010; RIDENTI, Marcelo. Em busca do povo Brasileiro: Artistas da revolução, do CPC à era da TV. São Paulo:Editora Unesp, 2014.
} 
“tropicalistas”, em 1967. Nessas interpretações, o filme Terra em Transe, de Glauber Rocha, a encenação de O rei da vela (escrita por Oswald de Andrade em 1937 e encenada em 1967) pelo Teatro Oficina, a obra ambiência Tropicália, composta por Hélio Oiticica, e as apresentações de Caetano Veloso e Gilberto Gil no III Festival de Música Popular da TV Record, configuraram o que ficou conhecido como "tropicalismo" em suas diferentes áreas.

Nosso trabalho surgiu a partir da necessidade de expandir e complementar os estudos que abrangem as relações entre as diferentes áreas da produção artística, destacando o intenso diálogo estabelecido entre o teatro e a música nos anos 1960. A partir da bibliografia existente, verificou-se a inexistência de uma análise aprofundada sobre as afinidades temáticas existentes entre as obras de Caetano Veloso e José Celso Martinez Corrêa (diretor do Teatro Oficina ${ }^{4}$ ), bem como das convergências que as declarações desses artistas apresentaram ao longo do período de 1966 a 1969.

O projeto de pesquisa ora em curso visa preencher a lacuna presente na bibliografia sobre a produção tropicalista, identificada acima. Considerando que a emergência dessas obras não foi uma questão de prática imediata, mas de intencionalidades 5 específicas que se opunham à produção nacional-

$4 \quad$ O grupo Oficina constituiu-se em 1958, na Faculdade de direito do Largo São Francisco, formado por um grupo de estudantes, dentre eles, José Celso Martinez Corrêa. Nascido em Araraquara, cidade do interior de São Paulo, José Celso veio para a capital ainda jovem, com dezessete anos, para cursar direito. No final dos anos 1950 e até meados dos anos 1960, José Celso se consolidou como diretor de teatro na produção cultural brasileira.

5 Ao produzir uma obra, o artista imprime determinadas intencionalidades. Essas intencionalidades são constituídas historicamente, frutos de práticas sociais. Ao serem expressas nas produções artísticas, essas intencionalidades adquirem materialidade. Através da análise das obras de arte, é possível reconstruir a materialidade das interpretações engendradas por determinados artistas acerca da realidade social. Nessa concepção, a obra de arte é uma resposta significativa a determinado contexto histórico, onde o artista traz consigo determinadas 
popular, num primeiro momento de nossa pesquisa, buscamos mapear os debates da época e os depoimentos enunciados anos depois pelos artistas em questão, buscando revelar a emergência preliminar (WILLIAMS, 1979, p.129) do tropicalismo, na música e no teatro, compreendido aqui como uma formação cultural ${ }^{6}$. Nessa primeira etapa da pesquisa, concentramos nossa atenção no ano de 1966 e no primeiro semestre de 1967. A análise dos debates e dos depoimentos permite-nos a reconstrução das intencionalidades desses artistas, revelando vários elementos que seriam maturados em meados de 1967, com a emergência do tropicalismo nas diferentes esferas da produção cultural.

Entretanto, antes de se considerar estes aspectos políticos e ideológicos perceptíveis a partir do ano de 1966, verifica-se que alguns anos antes, artistas e intelectuais, num processo intenso de politização à esquerda em grandes centros urbanos, dada a euforia do anúncio das reformas de base do governo de João Goulart (1961-1964), estavam organizados em torno de entidades como o Instituto Superior de Estudos Brasileiros (ISEB), os Centros Populares de Cultura da União Nacional dos Estudantes (CPC da UNE), além de movimentos vinculados à igreja católica e ao próprio Partido Comunista Brasileiro (PCB). Por meio dessas entre outras instituições ${ }^{7}$, a

intencionalidades que exercem pressões em relação aos limites concretos (WILLIAMS, 1979, p.116-117).

6 Essa forma de análise foi inaugurada por Raymond Williams (1992), e permite a análise fugir do engessamento das propostas artísticas enclausuradas na ideia de "movimento", a fim de identificar "a organização interna de determinada formação, e suas relações propostas e reais com outras organizações na mesma área e, de modo mais geral, com a sociedade" (WILLIAMS, 1992, p.68). A compreensão do grupo tropicalista como uma formação heterogênea permite a análise da relação entre o contexto histórico e a resposta individual e coletiva desses artistas, articulados em distintos canais da produção cultural.

7 Vários trabalhos tomaram essas instituições como objetos de análise. Dentre a bibliografia existente, consultar: GARCIA, Miliandre. Do teatro militante à música engajada: a experiência do CPC da UNE (1958-1964). 1. ed. São Paulo: Fundação Perseu Abramo, 2007; MARTINS FILHO, João Roberto. Movimento estudantil e militarização do Estado no Brasil: 1964-1968. Dissertação (Mestrado) Universidade Estadual de Campinas, 
valorização do povo passou a ser uma das bases constitutivas das utopias anticapitalistas progressistas e revolucionárias no alvorecer da década de 1960, situando no passado "as bases para construir o futuro de uma revolução nacional modernizante que, ao final do processo, poderia romper as fronteiras do capitalismo" (RIDENTI, 2010, p.88-89). À sombra dos conflitos geopolíticos engendrados pelos dois grandes blocos econômicos em meio à guerra-fria e aos ecos da revolução cubana em meio às transformações pelas quais atravessa a sociedade brasileira, frações intelectualizadas da classe média então incipiente aglutinaram artistas e intelectuais que produziram e organizaram um mercado de bens culturais tendo por base a valorização da "cultura nacional e popular" em resposta ao imperialismo que se desenvolvia em âmbito mundial e conquistava entusiastas e consumidores em solo brasileiro. Nesse processo ambivalente entre mercado e politização, gestou-se uma visão de Brasil pautada por uma série de projetos políticos e culturais heterogêneos em que a perspectiva cultural do nacional-popular era central. Ora, a cultura, a partir desse momento, passava a ser encarada como "um espaço privilegiado onde se processava a tomada de consciência dos indivíduos e se travava a luta política” (ORTIZ, 1986, p.56).

Nesse período que abrange o final da década de 1950 e início da década seguinte, o país assistiu à emergência de "um vasto contingente de produtores e consumidores de cultura, uma numerosa pequena burguesia intelectualizada" (FREDERICO, 1995, p.188) que propiciaram as bases para a criação de um mercado de bens culturais e o desenvolvimento de uma indústria cultural que dava seus primeiros passos no começo dos anos 1960. Conforme aponta Renato Ortiz (1988, p.132), ao longo da década de 1960 ocorreu uma considerável expansão da produção, distribuição e consumo de produtos culturais, ao mesmo tempo em que os grandes grupos 
empresariais, que passaram a deter o controle dos meios de comunicação, também voltaram suas atenções para a dimensão comercial da produção cultural popular. O aumento do consumo de eletrodomésticos, como a televisão ou os aparelhos sonoros, expressaram a consolidação de novos hábitos e padrões de consumo, em meio ao alargamento da produção cultural, que passava a abranger novas camadas sociais, faixas econômicas diferenciadas que eram encaradas como novos consumidores, integrados em um mercado nacional.

Contudo, com o golpe militar em 1964, testemunhou-se o rompimento dos elos que envolviam intelectuais e artistas com os movimentos populares, levando as esquerdas a uma sensação de perplexidade, abaladas no que tange à consciência de sua atividade política e artística (NAPOLITANO, 2010, p.40). O golpe e a não reação dos setores aglutinados em torno das esquerdas, trouxe aos artistas e intelectuais uma sensação de fracasso em relação a sua missão, qual seja, levar a consciência social ao povo brasileiro sob a égide das reformas de base ${ }^{8}$.

Antes do golpe, os artistas e intelectuais engajados dividiam "suas atividades entre o mercado e as organizações culturais situados fora dele" (NAPOLITANO, 2010, p.40). Isso quer dizer que existia um conjunto de intelectuais que organizavam a produção cultural, pensavam os limites e os alcances dessa cultura, e promoviam uma visão de Brasil pautada num viés político, ao mesmo tempo em que se consolidavam núcleos de consumo que divulgavam comercialmente essa produção cultural.

Cumpre lembrar que apesar da extinção das entidades organizativas das esquerdas (a exemplo do ISEB e do CPC da UNE, ambas na cidade do Rio de Janeiro) após o golpe de Estado, a expansão da produção e distribuição do

8 Dentre as pesquisas sobre esse efeito do golpe nas esquerdas, ver: REIS FILHO, Daniel Aarão. A revolução faltou ao encontro: os comunistas no Brasil. São Paulo: Brasiliense, 1990. 
consumo de bens culturais possibilitou o prolongamento da produção cultural nacional-popular majoritariamente de esquerda, levando a novos impasses em torno da relação entre engajamento político e mercado cultural. As dinâmicas empresariais do ramo cultural possibilitaram a articulação, ainda que de forma não organizada, de uma esfera pública na qual a própria noção de cultura popular foi reinterpretada. Tal iniciativa associada às demandas de artistas e intelectuais por espaços de representação, fomentou de forma gradativa a proposição de uma "autonomia" da esfera intelectual e artística no Brasil. Esse processo de construção de uma esfera pública de debates, demandada por setores da produção intelectual e artística com adesão ao nacional-popular, foi sendo paulatinamente engendrada em consonância com o mercado de bens culturais que vinha se desenvolvendo pari passu com a consolidação dessa esfera pública?

A partir desse panorama inicial é possível notar que no contexto imediato ao pós-golpe o debate político deslocou-se das instituições partidárias, fragilizadas com o golpe civil-militar, para os espaços da produção cultural. Tais espaços passaram a ganhar força política e ideológica, sobretudo após o golpe, em meio à repressão generalizada em relação às instituições aglutinadoras da esquerda, como a UNE, o CPC e o próprio PCB. Nesse processo, gestaram-se novos espaços de debates, marcado pela produção cultural que acenava para um mercado formulado por esses próprios artistas, que também se tornavam agente e produtores culturais.

\section{Nacionalismo e engajamento}

\footnotetext{
9 A sensação de "autonomia” advinda da declaração de 1958, e a construção dessa esfera pública de debates são exploradas por Rodrigo Czajka em: Páginas de resistência: Intelectuais e cultura na Revista Civilização Brasileira (1965-1968) (Mestrado), Universidade de Campinas, Instituto de Filosofia e Ciências Humanas, Campinas, 2005; Praticando delitos, formando opinião: Intelectuais, comunismo e repressão (1958-1968) (Doutorado), Universidade de Campinas, Instituto de Filosofia e Ciências Humanas, Campinas, 2010.
} 
Compreende-se que a relativa hegemonia de esquerda, a qual apontou Roberto Schwarz, era formada por diversos projetos no plano cultural e intelectual, como os espetáculos teatrais, sobretudo o show Opinião (1964) e o Arena conta Zumbi (1965) que, embora sob um pano de fundo engajado, apontavam diferentes formas no trato e seleção do material artístico. Situadas em contextos distintos, e com diferentes referências ideológicas, essas obras pertenceram a um grande caldo cultural identificado tradicionalmente com a produção nacional-popular.

O que ficou conhecido como nacional-popular aqui no Brasil - antes mesmo do debate proposto pela literatura em torno de Antonio Gramsci - tem sua raiz ainda no modernismo paulista dos anos 1920, com diversas peculiaridades que, em grande medida, divergem do viés politizado assumido ao longo da década de 1960, possuindo tons e matizes distintos nas diversas esferas artísticas, adquirindo conotações específicas, mediante as intencionalidades e posições dos artistas, assumidas historicamente. Definido por Marcos Napolitano como "mediação elaborada entre o local ('dialetal-folclórico') e o universal ('cosmopolita-burguês')” (NAPOLITANO, 2011, p.309), esse paradigma assentou-se, durante os anos 1960, na reação contra os processos da modernidade capitalista, como a urbanização desestruturada e a industrialização, pautadas na lógica do capital. As condições internacionais, nas quais o nacional-popular foi impresso nas obras desse período, segundo Marcelo Ridenti, são as seguintes:

\begin{abstract}
1) aprofundamento do processo de proletarização do trabalho intelectual e de reificação, inclusive no campo da produção da cultura, cada vez mais industrializada e mercantil; 2) repulsa político-moral ao capitalismo, que mostrava sua barbárie na Guerra do Vietnã; 3) revoluções no Terceiro Mundo como polos catalisadores positivos do anticapitalismo (RIDENTI, 2014, p.39).
\end{abstract}

Nesse processo, artistas e intelectuais passaram a se identificar com o homem rural, o camponês, o retirante ou homem do morro, "tomado como autêntico representante do povo oprimido, cujas raízes seria preciso 
recuperar" (RIDENTI, 2014, p.27-28). Filmes como Vidas Secas (1963), de Nelson Pereira dos Santos, Deus e o diabo na terra do sol (1964), de Glauber Rocha, e Os Fuzis (1964), de Ruy Guerra, são sintomáticos da entrada desses novos personagens em cena, inseridos em espaços como o morro e o sertão.

Em linhas gerais, as produções artísticas identificadas com o nacionalpopular envolveram uma série de grupos sociais e gêneros artísticos que buscavam nas raízes nacionais a criação de uma identidade nacional que se identificasse com o "povo", superando os arcaísmos do Brasil e seus "males de origem", bem como o subdesenvolvimento nacional, buscando conscientizar o público dos problemas nacionais ${ }^{10}$. A canção foi marcada por ritmos oriundos, sobretudo da bossa nova e de diversas matizes do samba. Já no teatro, em espetáculos como o Show Opinião e o Arena conta Zumbi, buscava-se efetuar uma recuperação de formas expressivas e musicais de cunho popular, do meio rural ao subúrbio das cidades. Marcos Napolitano aponta que os espetáculos musicais de teatro "marcaram a busca utópica da identidade popular mais genuína possível, que deveria nortear a postura do intelectual nacionalista" (NAPOLITANO, 2007, p.86).

Caetano Veloso e José Celso são artistas provenientes da produção nacionalpopular. Em depoimento a Marcelo Ridenti (2014, p.245), Carlos Nelson Coutinho lembra que Caetano frequentava o CPC no tempo em que morou em Salvador, e chegou a fazer um samba fortemente marcado pelo ideário nacional-popular ${ }^{11}$. O artista foi para São Paulo em 1965, acompanhar sua irmã, Maria Bethânia, chamada para substituir Nara Leão no Show Opinião. Lá, entrou em contato com Augusto Boal, e no mesmo ano, participou do musical Arena conta Bahia, dirigido por Boal. Em 1966, Caetano mudou-se

$10 \quad$ A edição dos Cadernos do povo brasileiro, intitulada Quem é o povo no Brasil (1962), redigida por Nelson Werneck Sodré e lançada junto à coleção divulgada pela editora Civilização Brasileira em parceria com o CPC e o ISEB entre 1962 e 1964, é sintomática desse debate que permeava as produções identificadas com o nacional-popular.

11 Ridenti (2014, p.245) aponta que o samba em questão é o Samba em paz, gravado num compacto lançado em 1965. 
para o Rio de Janeiro e, a partir daí, daria forma definitiva a sua carreira de músico $^{12}$. Já o teatro Oficina, do qual Zé Celso ainda é parte integrante, nasceu às margens do Arena, e manteve fortes relações com o grupo até 1961, ano de sua profissionalização. Nas palavras de Armando Sérgio da Silva:

Foi no Teatro de Arena, e principalmente através de Augusto Boal, que o futuro diretor [José Celso] buscou as bases de sua formação teatral: um certo grau de preocupação social e o domínio de uma técnica de trabalho com atores, a técnica do Actors Studio (SILVA, 2008, p.23)

A partir de 1966, observamos a gestação de um conjunto de ideias, por parte de Caetano, que marcaram seu distanciamento das produções nacionaispopulares. Nesse mesmo ano, o prédio do Oficina foi destruído por um incêndio. A reconstrução do teatro foi acompanhada de uma temporada no Rio de Janeiro, onde os membros do grupo e seu diretor, José Celso, puderam se apropriar de novos métodos de encenação e peças de teatro.

\section{Os impasses da música popular brasileira e o incêndio no teatro oficina}

Nos primeiros anos após o golpe de 1964, o teatro tornou-se o local que aglomerou a cultura engajada da época na busca pela ampliação do público. A encenação foi concatenada com a música, dando origem aos espetáculos citados anteriormente. No plano da música popular, programas como $O$ fino da Bossa e, posteriormente, os Festivais de Música Popular Brasileira, tornaram-se os canais de divulgação da canção engajada via televisão.

12 Marcos Napolitano recorda algumas produções que foram saudadas pelos jurados dos famosos festivais televisivos nesse período: "Um dia recebeu prêmio de melhor letra no Festival da TV Record de 1966, enquanto Boa Palavra se destacou no festival da TV Excelsior, no mesmo ano" (NAPOLITANO, 2010, p.108). 
Contudo, em $1966^{13}$, os efeitos que o mercado poderia ocasionar na produção engajada pareciam cada vez mais perceptíveis ${ }^{14}$. $\mathrm{O}$ avanço da jovem guarda ${ }^{15}$ e a popularidade que os artistas identificados com essa produção ganharam em meio à juventude, suscitou grande alarde nos meios artísticos e intelectuais identificados com o nacional-popular. Em meio aos impasses dos artistas engajados, o avanço da indústria cultural e a entrada da música popular dentro das estruturas mercadológicas, em maio de 1966, a Revista Civilização Brasileira promoveu um debate sobre os caminhos que deveriam orientar a música popular brasileira no pós-golpe.

O debate, intitulado Que caminho seguir na música popular brasileira? ${ }^{16}$, contou com a presença de Flávio Macedo Soares, Caetano Veloso, Nelson Lins e Barros, José Carlos Capinam, Gustavo Dahl, Nara Leão e Ferreira Gullar. Airton Lima Barbosa foi o coordenador do debate. Marcos Napolitano salienta que o objetivo do debate era "entender e equacionar os novos desafios que se colocavam diante da música jovem engajada, colocada na defensiva com o avanço comercial da Jovem Guarda” (NAPOLITANO, 2010, p. 98).

\footnotetext{
13 Marcos Napolitano (2010, p.74) aponta que o sucesso de Roberto Carlos em 1966, trouxe novos paradigmas para artistas e intelectuais engajados pensarem sobre a relação entre música enquanto produto vinculado à indústria e, ao mesmo tempo, expressão cultural de oposição ao regime.

14 Posteriormente, através das telenovelas, a produção nacional-popular acabou ganhando novo impulso.

15 Em setembro de 1965, estreou na TV Record, o programa Jovem Guarda, apresentado por Roberto Carlos, Erasmo Carlos e Wanderléia. Sua popularização foi acirrando a competição, fomentada pela mídia, com o programa O Fino da Bossa, apresentado por Elis Regina e Jair Rodrigues, lócus da música popular brasileira com certa politização.

16 Todos os trechos aqui reproduzidos foram retirados da seguinte edição: F.M.Regis (org). "Que caminho seguir na Música Popular Brasileira”, Revista Civilização Brasileira, no 7, maio/1966.
} 
Ao início do debate, Flávio Macedo Soares apontou o contexto de "crise" da canção popular, salientando a necessidade da organização dos artistas em torno de um ideal comum e o entrosamento entre as diversas formas de manifestações artísticas e culturais. Comentando a exposição feita por Flavio Macedo, Caetano Veloso propôs a necessidade de maior organicidade na organização cultural, ensejando a criação de "uma organicidade de cultura brasileira, uma estruturação que possibilite o trabalho em conjunto, inter-relacionado as artes e os ramos intelectuais" (1966, p.378).

Caetano ainda apontou a necessidade da compreensão histórica da cultura e da música popular brasileira, e como essa processualidade lançaria uma “possibilidade seletiva” (1966, p.378), baseada nessa mesma tradição. A partir desse argumento, o artista ensejou a retomada da linha evolutiva, que possibilitaria a "organicidade para selecionar e ter um julgamento de criação" (1966, p.378).

Segundo Marcos Napolitano, o conceito de "linha evolutiva" é uma problemática presente no conjunto dos debates que emergiram após a Bossa-Nova e tornou-se "uma ideia força que vem orientando, desde então, a vontade de atualização da música popular sem, no entanto, negar a presença da tradição, expressa sobretudo pelo samba urbano que emergiu nos anos 30" (NAPOLITANO, 2010, p.98). Ao colocar em questão a retomada da "linha evolutiva", Caetano indicou a volta ao "momento João Gilberto”. Segundo o artista, foi nesse momento que a música passou por uma recriação, alcançando a modernidade musical, dando um passo à frente na música popular produzida até os anos 1950. Ao sugerir a retomada desse momento, Caetano indicava o procedimento no qual João Gilberto baseou sua interpretação, cujo eixo era "a ideia de seletividade consciente, filtrada por uma informação técnico-musical avançada na busca de uma síntese atualizada em relação às tendências mais criativas da música popular dos grandes centros internacionais", (NAPOLITANO, 2010, p.103) conjugando com o contexto nacional. Nas palavras de Caetano: 
Só a retomada da linha evolutiva pode nos dar uma organicidade para selecionar e ter um julgamento de criação [...] João Gilberto para mim é exatamente o momento em que isso aconteceu: a informação da modernidade musical utilizada na recriação, na renovação, no dar um passo à frente da música popular brasileira. Creio mesmo que a retomada da tradição da música brasileira deverá ser feita na medida em que João Gilberto fez (1966, p.378)

Para Caetano, o artista deveria ter o domínio dos elementos constitutivos da tradição, a fim de escapar das vicissitudes do mercado (NAPOLITANO, 2010, p.103). O trecho da fala de Caetano no debate é sintomático, consideradas as questões oriundas da formação nacional-popular, como a atuação do artista frente às estruturas da indústria fonográfica, os impasses da arte frente ao mercado, e o domínio, por parte do artista, do conjunto de técnicas que informam a criação artística:

\begin{abstract}
Acho absurda a afirmação de que todo grande sucesso corresponde a uma grandeza qualitativa. Sem dúvida as ondas publicitárias só acontecem possibilitadas por exigências de época, mas isso não quer dizer que elas não existam e não funcionem. É preciso saber a que servem, de que servem as grandes promoções de nomes e obras - não raro das piores coisas. [...] A alienação também é um dado real, é coisa definida e talvez seja o conceito que melhor defina a realidade brasileira. Eu não tenho dúvida de que muitos dos grandes sucessos se servem dela, servindo-a. O fato de saber que eles correspondem a exigências da realidade não me obriga a compactuar com eles. Pelo contrário - é exatamente criando uma cultura, correspondente com a necessidade que começam a ter os jovens brasileiros, que eu encontro minha única possibilidade - justa de estar integrado nela. Sei que a arte que eu faço agora não pode pertencer verdadeiramente ao povo. Sei também que a Arte não salva nada nem ninguém mas que é uma das nossas faces. Me interessa que corresponda o que faço à posição tomada por mim diante da realidade brasileira (1966, p.383-384).
\end{abstract}

Caetano buscava retomar uma tradição musical sintetizada na figura de João Gilberto, trazendo à tona os elementos da "modernidade musical", a fim de renovar a música popular brasileira colocando em questão os elementos musicais presentes no nacional-popular, que foram apropriados 
da tradição cultural brasileira, e os componentes que foram relegados ao segundo plano.

No mesmo mês do debate analisado acima, um incêndio destruiu o prédio do teatro Oficina. As palavras de José Celso são sintomáticas do impacto que o evento teve para o grupo como um todo: "O Oficina queimou. Com o fogo, foi tudo aquilo. O golpe e a resistência primeira ao golpe. Vinha vindo outra coisa... Ninguém sabia..." (CORREA, 1998 [1983], p.78).

Com o incêndio, os membros do Oficina e os artistas vinculados aos demais teatros de São Paulo passaram a efetuar uma série de ações colaborativas com o objetivo de arrecadarem fundos para a reconstrução do teatro. Para nossa discussão, nos interessa o período que o Oficina reencenou algumas peças no primeiro semestre de 1967. Durante essa temporada, os membros do Oficina participaram de um laboratório de "Interpretação Social", oferecido por Luiz Carlos Maciel, e um curso introdutório sobre materialismo histórico, intitulado "Filosofia e Pensamento Social" ministrado por Leandro Konder (PATRIOTA, 2003, p.142).

Ao mesmo tempo em que os artistas participavam desses eventos de formação, realizavam a reencenação de Pequenos Burgueses, Andorra, e de uma nova versão de Quatro num Quarto, agora dirigida por José Celso. Nessa reencenação, o diretor imprimiu um tom de chanchada na peça. $\mathrm{O}$ relato de Fernando Peixoto nos oferece um panorama das experimentações realizadas no palco:

\footnotetext{
nos soltamos em todos os níveis, além do limite do 'bom comportamento' cênico, transformando o texto de Katáiev no veículo para um exercício de surrealismo e criatividade, improvisando a todo instante, tomando como estímulo qualquer acontecimento [...] É impossível descrever o que acontecia em cada espetáculo: o certo é que esta explosiva versão da comédia de Katáiev foi, em alguns níveis, um necessário embrião para a ruptura com a interpretação mais tradicional que empreenderíamos, em seguida, na montagem debochada e irreverente de O Rei da Vela (PEIXOTO, 1982, p.70-71).
} 
Através do relato de Fernando Peixoto, podemos observar que a encenação da peça trouxe consigo elementos emergentes que foram, posteriormente, desenvolvidos em peças identificadas com o tropicalismo no teatro, como a chanchada e o rompimento com o que Fernando Peixoto chama de "bom comportamento cênico”. José Celso recorda que as experiências vivenciadas no Rio de Janeiro foram centrais para o giro de posição assumido em suas encenações a partir de 1967, com a direção de O rei da vela. Nas palavras do diretor:

\begin{abstract}
Nós procurávamos uma peça que traduzisse toda a nossa vontade de rompimento conosco mesmo. Fizemos, no grupo, uma espécie de revolução cultural. Principalmente num laboratório, uma "psicoterapia de grupo" que começamos no Rio, com o Luís Carlos Maciel. Faltava o texto. O rei da vela foi encontrado [...] Com $O$ rei da vela a ruptura foi total. Não somente com toda uma linha que vinha seguindo o Oficina, mas com todo um caminho da cultura brasileira diretamente comprometida com o Estado Novo e com os desenvolvimentos posteriores (CORREA, 1998 [1968], p.100-101).
\end{abstract}

A análise de Armando Sérgio da Silva corrobora com a nossa hipótese de que esse período no Rio de Janeiro preparou a futura encenação de $O$ rei $d a$ vela. Para o autor, de um lado, os artistas alteraram a forma de abordar o personagem, ampliando a visão oferecida pelo método de Stanislavski. De outro, e o que mais nos interessa para a presente discussão, passaram a se debruçar sobre a realidade brasileira a partir da própria produção cultural nacional (SILVA, 1981, p.47).

Se pensarmos nas produções dirigidas por José Celso antes de $1966^{17}$, podemos notar que as únicas peças nacionais dirigidas são aquelas que

\footnotetext{
17 Suas primeiras peças autorais, Vento forte para papagaio subir e $A$ incubadeira, encenadas, respectivamente em 1958 e 1959, foram marcadas pela temática da ruptura com o círculo familiar e pela influência de Jean-Paul Sartre. Inclusive, em 196o, com a vinda do filósofo francês para o Brasil, José Celso traduziu e adaptou, junto com Augusto Boal, o roteiro cinematográfico de $A$ engrenagem. No final dos anos 1950 e até meados dos anos 1960, José Celso se consolidou como diretor teatral na produção cultural brasileira. Em 1961, dirigiu A vida impressa em dólar, de Clifford Odetts; no mesmo ano, o grupo Oficina se profissionalizou; em 1962, dirigiu Todo anjo é terrível, de Ketti Frings. Após a direção dessas
} 
possuem sua própria autoria. Passando pelo teatro norte-americano, suíço e russo, o diretor transitou entre métodos de interpretação, buscando trabalhar aspectos do contexto histórico dos anos 1960 a partir de peças estrangeiras. A descoberta do "elemento brasileiro", simbolizado na encenação de $O$ rei da vela, deve ser balizada historicamente tendo em mente a busca de uma renovação no interior das suas encenações anteriores $^{18}$ e o diálogo que o diretor, junto com o teatro Oficina, estava mantendo em relação aos demais artistas e intelectuais nos anos 1960. Neste aspecto, concordamos com a análise de Rosangela Patriota (2003, p.145), quando a autora propõe que o impacto do filme Terra em Transe ${ }^{19}$, de Glauber Rocha, e o contato com a obra de artistas como Antonin Artaud, Bertolt Brecht e Jerry Grotowski, via o laboratório de Luís Carlos Maciel, configuram-se como importantes elementos que deram origem a encenação da peça de Oswald no segundo semestre de 1967.

peças norte-americanas, em 1963, dirigiu Pequenos Burgueses, do russo Máximo Gorkí. Em 1964, sob o impacto do golpe militar, José Celso dirigiu Andorra, de Marx Frisch. Com o sucesso da peça, o diretor ganhou uma bolsa de estudos do governo francês. Em 1965, viajou para a Europa e realizou um estágio no Berliner Ensemble. De volta para o Brasil, no mesmo ano, traduziu junto com Fernando Peixoto Os Inimigos de máximo Gorki, encenada em 1966.

18 O seguinte trecho da entrevista de José Celso a Tite Lemos, em 1968, é sintomático dessa busca pela renovação das suas encenações: "Era terrível para mim ver a plateia dos sábados se deliciando com a mensagem boboca, nojenta mesmo, que Ralph, personagem da Vida impressa em dólar, concluía no final da peça" (CORREA, 1998, p.10o).

19 Não há espaço, no presente trabalho, para analisarmos o impacto que Terra em Transe causou em Caetano e José Celso. Ao longo de nossa pesquisa buscaremos desenvolver esse ponto que nos parece ser um dado central na emergência do tropicalismo. Em seu livro de memórias, Caetano declarou que "Se o tropicalismo se deveu em alguma medida a meus atos e minhas ideias, temos então de considerar como deflagrador do movimento o impacto que teve sobre mim o filme Terra em Transe, de Glauber Rocha" (VELOSO, 2012, p.94). 


\section{Considerações finais}

As declarações de Caetano no debate de 1966, citado anteriormente, nos trazem algumas questões que foram maturadas posteriormente, em 1967, com a apresentação de Alegria, alegria. O artista propôs a ideia de “possibilidade seletiva”, conjugando os ganhos trazidos pela bossa-nova com as inovações técnicas e musicais desenvolvidas no plano internacional. Não se trata do culto aos elementos populares ou folclóricos, mas de uma seleção consciente, onde o artista deve estar alinhado com as produções culturais internacionais. A proposta de Caetano apontava para o início de uma seletividade entre os novos elementos da modernidade urbanoindustrial e a sofisticação rítmica, musical e poética iniciada com João Gilberto, presentes no nacional-popular, frutificada no III Festival, em 1967. De outro lado, no início de 1967, durante a temporada no Rio de Janeiro, José Celso pôde entrar em contato com novos métodos de interpretação, obras e perspectivas teóricas. Essa experiência reverberou na encenação de Quatro num quarto, onde o diretor se afastou no método de Stanislavski e mobilizou a chanchada, elemento amplamente explorado posteriormente, na encenação de $O$ rei da vela.

As falas de Caetano no debate, e os relatos de José Celso e Fernando Peixoto, apontam para um conjunto de intencionalidades que seriam maturadas na segunda metade de 1967, com a apresentação de Alegria, alegria e a encenação de $O$ rei da vela. Como vimos, em 1966, esses artistas começaram a se distanciar das produções nacionais-populares e apostar em outras hipóteses e caminhos para a produção cultural brasileira. Situados em distintos canais de produção e circulação, o posicionamento dos artistas, cotejado no debate e nos relatos, é sintomático da emergência preliminar da formação cultural tropicalista. 


\section{REFERÊNCIAS}

CORRÊA, José Celso Martinez. Zé Celso Martinez Corrêa Primeiro Ato: Cadernos, Depoimentos, Entrevistas (1958-1974); seleção, organização e notas por STAAL, Ana Helena Camargo de. São Paulo: Editora 34, 1998.

DUNN, Christopher. Brutalidade Jardim: a Tropicália e o surgimento da contracultura brasileira. São Paulo: Editora Unesp, 2009.

F.M. Regis (org). “Que caminhos seguir na Música Popular Brasileira”. IN: Revista Civilização Brasileira, nº̄7, maio, 1966.

FAVARETTO, Celso. Tropicália: alegoria, alegria. 2. ed. Cotia: Atelie Editorial, 1996.

GARCIA, Miliandre. Do teatro militante à música engajada: a experiência do CPC da UNE (1958-1964). 1. ed. São Paulo: Fundação Perseu Abramo, 2007.

MARTINS FILHO, João Roberto. Movimento estudantil e militarização do Estado no Brasil: 1964-1968. Dissertação (Mestrado), Instituto de Filosofia e Ciências Humanas, Universidade Estadual de Campinas, Campinas, 1986.

MORELLI, Rita. C. L. Indústria Fonográfica: um estudo antropológico. Campinas-SP: Editora Unicamp, 2009.

NAPOLITANO, Marcos; VILLACA, Mariana Martins. Tropicalismo: As Relíquias do Brasil em Debate. Revista Brasileira de História, São Paulo, 1998, n.35, p. 53-75.

NAPOLITANO, Marcos. A Síncope das ideias: a questão da tradição na música popular brasileira. São Paulo: Fundação Perseu Abramo, 2007.

. Seguindo a canção: Engajamento político e indústria cultural na MPB (1959-1969). São Paulo: Versão digital revista pelo autor, 2010. 
. Coração civil: arte, resistência e lutas culturais durante o regime militar brasileiro (1964-1980). Tese de Livre docência. Departamento de História. Universidade de São Paulo, 2011.

ORTIZ, Renato. A moderna tradição brasileira. São Paulo: Brasiliense, 1988.

Cultura brasileira e identidade nacional. 2. ed. São Paulo: Brasiliense, 1986.

RIDENTI, Marcelo. Brasilidade Revolucionária: um século de cultura e política. São Paulo: Editora UNESP, 2010.

Em busca do povo Brasileiro: Artistas da revolução, do CPC à era da TV. São Paulo:Editora Unesp, 2014.

SCHWARZ, Roberto. O pai de família e outros estudos. São Paulo: Companhia das Letras, 2008.

SILVA, Armando Sérgio da. Oficina: do Teatro ao Te-Ato. São Paulo: Perspectiva, 2008.

SODRÉ, Nelson W. Quem é o povo no Brasil. Cadernos do Povo Brasileiro, UNE, 1963.

TOLEDO, Caio Navarro. ISEB: fábrica de ideologias. Campinas, Editora da UNICAMP, 1977 .

VELOSO, Caetano. Verdade Tropical. São Paulo: Companhia das Letras, 1997.

WILLIAMS, Raymond. Cultura. Tradução: Lólio Lourenço de Oliveira. Rio de Janeiro: Paz e Terra, 1992.

. Marxismo e Literatura. Rio de Janeiro: Zahar, 1979. 